\title{
The Cretaceous-Tertiary extinction: Modeling carbon flux and ecological response
}

\author{
J. Brad Adams and Michael E. Mann \\ Department of Environmental Sciences, University of Virginia, Charlottesville, Virginia, USA
}

Steven D'Hondt

Graduate School of Oceanography, University of Rhode Island, Narragansett, Rhode Island, USA

Received 16 September 2002; revised 14 May 2003; accepted 29 September 2003; published 17 January 2004.

[1] It is widely recognized that a significant negative excursion in carbon isotopic $\left(\delta^{13} \mathrm{C}\right)$ differences between planktic and benthic foraminiferal tests occurred at the Cretaceous-Tertiary (K-T) boundary. We applied parametric and nonparametric breakpoint tests and statistical comparisons of different recovery models to assess the timing and pattern of recovery from this negative excursion at South Atlantic Deep Sea Drilling Project (DSDP) Site 528 and equatorial Pacific DSDP Site 577. Our results indicate a two-stage recovery with an initial recovery to an intermediate state of planktic-to-benthic $\delta^{13} \mathrm{C}$ differences followed by a discontinuous shift to a final state with planktic-to-benthic $\delta^{13} \mathrm{C}$ differences similar to preextinction values. The final discontinuous shift in both the Pacific and Atlantic Ocean sites occurred several million years after the K-T collapse of planktic-tobenthic $\delta^{13} \mathrm{C}$ differences. Both the first and second stages of recovery are best described by damped exponential relaxations. The pattern and timing of this carbon cycle recovery may have been contingent on the occurrence of key biological events. INDEX TERMS: 4267 Oceanography: General: Paleoceanography; 1630 Global Change: Impact phenomena; 4806 Oceanography: Biological and Chemical: Carbon cycling; 4815 Oceanography: Biological and Chemical: Ecosystems, structure and dynamics; 1635 Global Change: Oceans (4203); KEYWORDS: extinction, ecosystem recovery, isotopes, model, foram

Citation: Adams, J. B., M. E. Mann, and S. D’Hondt (2004), The Cretaceous-Tertiary extinction: Modeling carbon flux and ecological response, Paleoceanography, 19, PA1002, doi:10.1029/2002PA000849.

\section{Introduction}

[2] Many studies have shown that carbon isotopic $\left(\delta^{13} \mathrm{C}\right)$ signatures of planktic marine carbonates rapidly declined by nearly $2 \%$ at the time of the Cretaceous-Tertiary (K-T) (Maastrichtian-Paleocene) boundary event [Arthur, 1979; Boersma et al., 1979; Hsü et al., 1982; Zachos et al., 1985, 1989; Zachos and Arthur, 1986; Arthur et al., 1987; Keller and Lindinger, 1989; D'Hondt et al., 1998]. The $\delta^{13} \mathrm{C}$ record of benthic marine carbonates did not decline in parallel with the planktic records [Zachos et al., 1985, 1989; Zachos and Arthur, 1986; Arthur et al., 1987; D'Hondt et al., 1998]. In effect, the $\delta^{13} \mathrm{C}$ differences between planktic and benthic carbonates declined strongly at the time of the K-T (Chicxulub) impact event [Zachos et al., 1985, 1989; Zachos and Arthur, 1986; Arthur et al., 1987; Stott and Kennett, 1989; D'Hondt et al., 1996]. The $\delta^{13} \mathrm{C}$ records of benthic carbonates from different ocean basins similarly converged at the approximate time of impact [Stott and Kennett, 1989; Zachos et al., 1992]. After converging at the time of the K-T impact event, differences between planktic and benthic records eventually increased over hundreds of thousands of years [Zachos et al., 1989; Stott and Kennett, 1990; D'Hondt et al., 1998]. They did not fully recover for more than $3 \mathrm{Myr}$ after the impact event [Boersma et al., 1979; D'Hondt et al., 1998].

Copyright 2004 by the American Geophysical Union. 0883-8305/04/2002PA000849\$12.00
[3] These records of planktic-to-benthic $\delta^{13} \mathrm{C}$ differences have been consistently interpreted to indicate that the flux of organic carbon from the surface ocean to the deep ocean catastrophically declined at the time of impact and did not fully recover until the $\delta^{13} \mathrm{C}$ differences again approached preimpact values [e.g., Zachos et al., 1989; D'Hondt, 1998]. The records of interbasin benthic $\delta^{13} \mathrm{C}$ differences have been similarly interpreted [Stott and Kennett, 1989; Zachos et al., 1992].

[4] The unusually low postimpact flux of organic carbon to the deep ocean has historically been ascribed to unusually low biological productivity (the "Strangelove ocean" model of Broecker and Peng [1982]) [Hsü et al., 1982; Boersma, 1984; Hsü and McKenzie, 1985; Zachos et al., 1985, 1989, 1992; Zachos and Arthur, 1986; Arthur et al., 1987; Stott and Kennett, 1989, 1990; Barrera and Keller, 1994]. Many researchers inferred from their $\delta^{13} \mathrm{C}$ records and other sedimentary data that a Strangelove ocean lingered for hundreds of thousands of years (or more) after the K-T impact event [e.g., Zachos and Arthur, 1986; Arthur et al., 1987; Stott and Kennett, 1989; Zachos et al., 1989].

[5] Studies of this carbon event have generally accepted the Strangelove ocean model as necessarily applying to any hypothetical interval of dust- and sulfate-induced darkness that briefly followed the K-T impact. However, planktic-tobenthic $\delta^{13} \mathrm{C}$ differences (and, by inference, the global flux of organic carbon to the deep ocean) remained unusually low for more than $3 \mathrm{Myr}$ after daylight returned. This long interval of a low deep-sea carbon flux in a day-lit ocean has 
been interpreted as due to an unusually low flux of organic carbon to the deep sea in an ecologically altered normal productivity ocean (the "living ocean" model of D'Hondt et al. [1998]). Others might interpret it as due to the extraordinary persistence of a low-productivity Strangelove ocean.

[6] Proximate physical effects of the K-T (Chicxulub) impact have been extensively modeled. The durations of most such effects range from less than a second (the initial impact) to no more than a decade (global darkness, acid rain) [Melosh, 1989; Kring, 2000]. No proximate effects of any large-body impact have been sustained on multimillion year timescales in any quantitative models of impact phenomena.

[7] In contrast, empirical studies of biological diversity have consistently shown that the major mass extinctions are followed by multimillion year lags in diversification [e.g., Sepkoski, 1998; Erwin, 1998; Kirchner and Weil, 2000; Erwin, 2000]. Such lags in diversification are consistent with coupled logistical models of continuous sigmoidally increasing diversity, in which an early interval of little apparent diversification is followed by a late interval of rapid diversification [Erwin, 2000]. These lags are also consistent with models of multistage recovery of ecosystem structures, in which the first occurrence of a key ecological function may force a rapid reorganization of ecosystem structure and initiate a new round of biological diversification. In the latter models, measures of ecological structure may exhibit more than one equilibrium state, and biological diversification need not be continuous.

[8] These comparisons of $\delta^{13} \mathrm{C}$ recovery, impact consequences, and biological diversification raise several related questions. Do $\delta^{13} \mathrm{C}$ records of the early Paleocene marine carbon cycle exhibit a pattern of continuous recovery or of discontinuous recovery? Do these records exhibit any evidence of more than one equilibrium state? Given the relatively brief duration of proximate impact consequences, how can a living ocean model and/or a low-productivity Strangelove ocean model be used to explain a multimillion year interval of an unusually low organic flux to the deep sea? Finally, how might these $\delta^{13} \mathrm{C}$ recovery models be related to models of biological recovery?

[9] In order to address these questions, we statistically assessed patterns of early Paleocene $\delta^{13} \mathrm{C}$ recovery at southeastern Atlantic Deep Sea Drilling Project (DSDP) Site 528 and central Pacific DSDP Site 577. In these studies we statistically determined breakpoints in the recovery of $\delta^{13} \mathrm{C}$ differences between planktic foraminiferal carbonates and benthic foraminiferal carbonates, and we statistically compared the recovery patterns of $\delta^{13} \mathrm{C}$ differences to continuous and discontinuous one-stage and two-stage recovery models.

\section{Data and Methods}

[10] Isotopic records used for this analysis are from DSDP Site 528, located on the Walvis Ridge in the southeastern Atlantic, and DSDP Site 577, located on Shatsky Rise in the central Pacific [D'Hondt et al., 1998]. These isotopic difference records were calculated by D'Hondt et al. [1998] using individual isotopic data from Shackleton et al. [1985], Miller et al. [1987], Corfield and Cartlidge [1992], Zachos et al. [1989], and D'Hondt and Lindinger [1994]. We make use of chronostratigraphic information from Berggren et al. [1995], Bleil [1985], Cande and Kent [1995], and Chave [1984].

[11] The current water depths for these two sites are given by Moore et al. [1984] and Heath et al. [1985]. Site 528 is at $3800 \mathrm{~m}$ below seafloor (mbsf); its paleodepth at the time of the K-T boundary event was $\sim 2700 \mathrm{mbsf}$. Site 577 is at 2675 mbsf; its paleodepth at the time of the K-T boundary event was $\sim 2750$ mbsf. The paleodepths are based on the subsidence curves and isostatic adjustment procedures of Sclater et al. [1985] and R. Dietmar Mueller et al. (digital map of the ocean floor available in 1992 from the Internet by anonymous ftp at URL address baltica.ucsd.edu/pub/ global_age) and sedimentary data from Moore et al. [1984] and Heath et al. [1985] for DSDP Leg 74 and DSDP Leg 86 , respectively.

[12] Factors that can affect the values of foraminiferal tests include the $\delta^{13} \mathrm{C}$ of dissolved inorganic carbon (DIC) in the foraminifer's environment, the extent of any photosymbiont activity within the foraminiferal protoplasm, the test calcification rate, and any contribution of respiratory carbon during calcification. The influence of these factors generally depends on the species and test size examined. Fortunately, the $\delta^{13} \mathrm{C}$ of DIC and the extent of photosymbiont activity vary predictably with depth (both photosymbiont activity and the $\delta^{13} \mathrm{C}$ of DIC decrease with increasing depth in the water column).

[13] To minimize the effect of these factors on our analysis of recovery patterns, we separately analyzed three different categories of planktic-to-benthic $\delta^{13} \mathrm{C}$ difference records. The first category contains planktic-to-benthic records defined by planktic species that are inferred to have dwelt near the ocean surface. These near-surface planktic species included taxa inferred to have been photosymbiotic (Paleocene Morozovella species) and taxa inferred to have been asymbiotic (Cretaceous Rugoglobigerina rotundata and Paleocene Praemurica taurica) [D'Hondt et al., 1994; D'Hondt and Zachos, 1998]. This category contains two records: the Site 528 surface-benthic record and the Site 577 surface-benthic record. The second category is defined by planktic species inferred to have dwelt near the ocean surface and to have been asymbiotic (the Site 528 asymbiotic surface-benthic record). These planktic species were Cretaceous Rugoglobigerina rotundata and Paleocene Praemurica taurica at both sites [D'Hondt and Zachos, 1993, 1998]. The third category is defined by planktic species that are inferred to have lived deeper in the water column and not to have been significantly photosymbiotic (e.g., the "intermediate-depth" species of D'Hondt et al. [1998]). These species included Cretaceous Pseudotextularia elegans and Paleocene Eoglobigerina eobulloides and Parasubbotina pseudobulloides at Site 528 and Cretaceous Pseudotextularia and Paleocene Subbotina species at Site 577 [D'Hondt and Zachos, 1993, 1998]. This third category contains two records: the Site 528 intermediate-benthic record and the Site 577 intermediate-benthic record.

[14] For the purposes of our modeling, the standard measure of location within each core (mbsf) is converted 
Table 1. Breakpoint Analyses Results

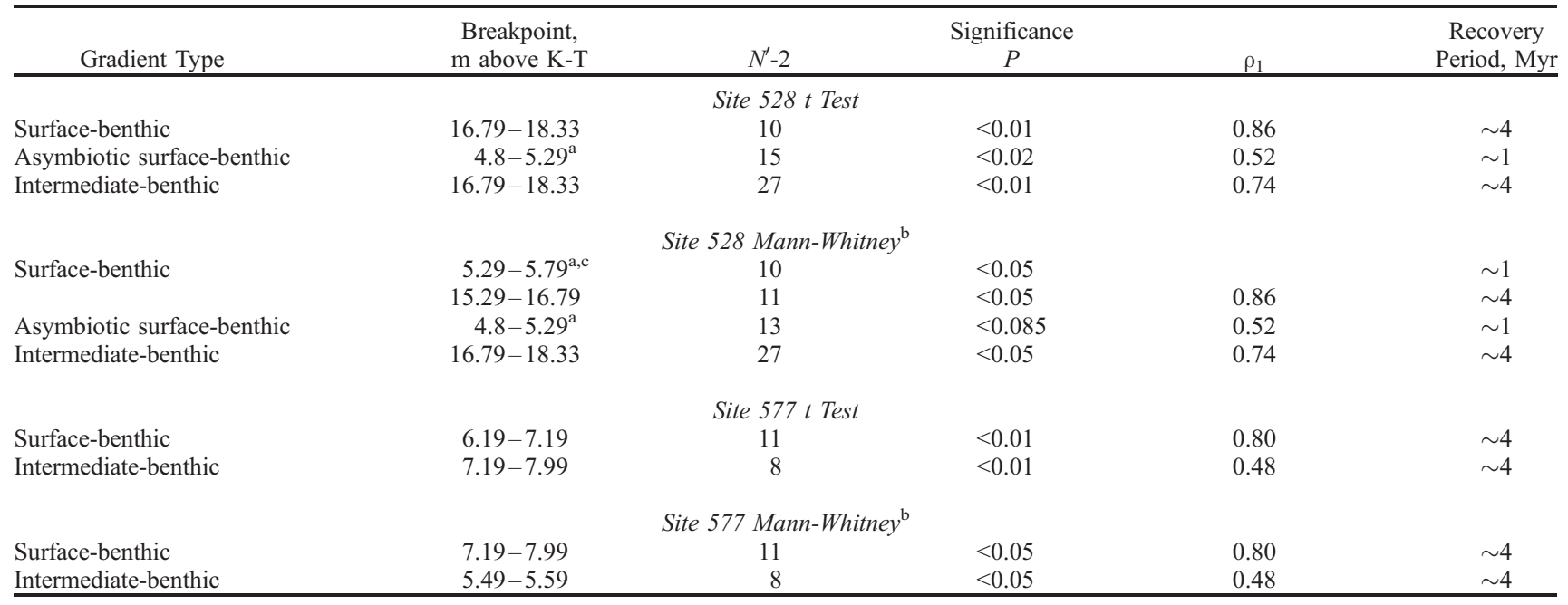

${ }^{a}$ Breakpoint coincident with early recovery period (see section 3 ).

${ }^{\mathrm{b}}$ Mann-Whitney results include significance correction for multiple comparisons.

${ }^{\mathrm{c}}$ Secondary breakpoint of qualitative prominence in breakpoint results.

to meters above the K-T boundary. Thus for example, the $\mathrm{K}-\mathrm{T}$ boundary is located at zero on the time-related sedimentation axis. Age estimates of different stratigraphic layers are based on the stratigraphic data of D'Hondt et al. [1998] and the age model of Berggren and Norris [1999].

\subsection{Breakpoint Analysis}

[15] Two iterative breakpoint techniques were employed to select the "initial" and "final" recovery regions for each data set: a serially dependent $t$ test-based analysis and a Mann-Whitney $U$ test-based analysis. The latter ensures the strength of the breakpoint analysis in light of the fact that the data do not meet the $t$ test's assumption of normally distributed data [see Wilks, 1995, Table 8]. The breakpoint analyses were both performed using scripts modeled after these two difference-of-mean methods described by Wilks [1995].

[16] The significance of a breakpoint between every pair of data points in each series was calculated and compared with all other potential breakpoints. The most significant breakpoint was selected for each of the four series. Because the data are all significantly serially correlated, an effective sample size that considers serial correlation was incorporated into the breakpoint analysis. The effective sample size was determined by

$$
N^{\prime}=N\left(1-r_{1}\right) /\left(1+r_{1}\right)
$$

where $N$ is the sample size and $r_{1}$ is the lag 1 correlation coefficient.

[17] This analytical approach identifies both positive breakpoints (intervals of $\delta^{13} \mathrm{C}$ difference recovery) and negative breakpoints (intervals of $\delta^{13} \mathrm{C}$ difference collapse). The recovery breakpoints yield estimates of the times of recovery of $\delta^{13} \mathrm{C}$ differences between planktic and benthic carbonates. The collapse breakpoint similarly yields an estimate of the time(s) of collapse of planktic-to-benthic $\delta^{13} \mathrm{C}$ differences.

[18] This method of breakpoint determination is vulnerable to statistical complications associated with multiple comparisons. In the Mann-Whitney breakpoint tests we thus employ a common multiple comparisons adjustment procedure: the Bonferroni adjustment. We use this adjustment to safeguard against undue magnification of the type I error rate, i.e., the probability of rejecting our null hypothesis of no difference of means between the two populations when it is, in fact, true. The procedure is to multiply the unadjusted $P$ values for each breakpoint determined by the number of tests (here, $\left.m=N^{\prime}\right)$ and compare this value $(m P)$ to the selected significance level $(\alpha=0.05)$. The significance values shown for the Mann-Whitney results are adjusted in this manner. The $t$ test results and unadjusted Mann-Whitney test results were of very similar magnitude. Consequently, comparison of the $t$ test results and the adjusted Mann-Whitney results in Table 1 allows for a comparison of significance values determined with and without consideration of the multiplicity problem. Relying on the Mann-Whitney results safeguards against the multiplicity problem as well as any issues arising from nonnormal residuals. A more detailed discussion of the multiplicity issue is given by Cook and Farewell [1996].

\subsection{Model Selection}

[19] The statistically determined breakpoints of each series were incorporated into a "best fit" analysis of four different model types. In order of increasing statistical complexity, these models are (1) a discontinuous one-stage recovery model consisting of distinct initial depressed and final recovered mean states ("two-mean recovery model"), (2) a continuous one-stage recovery model consisting of a damped exponential relaxation from the initial depressed to final recovered state ("single-exponential recovery model"), (3) a two-stage recovery model consisting of an initial damped relaxation to an intermediate depressed 
state followed by a discontinuous adjustment to a final mean state ("initial exponential recovery model"), and (4) a twostage recovery model consisting of an initial damped relaxation to an intermediate depressed state followed by a discontinuous adjustment and subsequent relaxation to a final state ("double-exponential recovery model"). The two-mean recovery models for the Site 528 asymbiotic surface-benthic and intermediate-benthic models actually include three means because there are data points before the K-T boundary for these series. However, the recovery model is consistent with the other analyses in that two mean states are modeled after the boundary. Figures 1-5 are graphical examples of the models.

[20] The "relaxation" components of the statistical models follow the damped exponential form:

$$
Y=A-B \exp (-\alpha x)
$$

The best parameters of this exponential form were calculated for each individual model by also using the chi-square test of best fit. A wide range of values of $A, B$, and $\alpha$ were used to minimize the mean square error of a fit of equation (2) using an iterative global minimization procedure. This procedure calculates the mean square error for a wide range of values of each variable and selects the combination of values that minimizes the mean square error. The selected parameters are then used to test the four model types using a $\chi^{2}$ goodness-of-fit test according to

$$
\chi^{2}=\Sigma\left\{1 / \sigma^{2}\left[y_{i}-y\left(x_{i}\right)\right]^{2}\right\}
$$

where $\sigma^{2}$ is the variance of the observed series, $y_{i}$ is the observed series, and $y\left(x_{i}\right)$ is the theoretical series [Bevington, 1969]. The reduced chi-square statistic (see below) was evaluated at the effective sample size $N^{\prime}$ to account for the effects of serial correlation. The reduced chisquare statistic is calculated according to

$$
\chi^{2} v=\chi^{2} / v
$$

where $v$ is the effective degrees of freedom:

[21] We determined the "best" recovery model by comparing the strength of the fit of each model. To gauge the best fit, the reduced chi-square value was computed and analyzed using the serially dependent number of degrees of freedom (i.e., $N^{\prime}$ ). For each analysis, values of $P$ closest to one were considered the best models (i.e., the least significantly different from the actual data).

\section{Results}

\subsection{Breakpoint Analysis}

[22] All four data series have statistically significant recovery breakpoints (Table 1). The significance values represent the probability that the two means on either side of the breakpoint are from the same distribution. Only three of the five series were Gaussian normally distributed; the other three were slightly non-Gaussian. Because nonnormal data are in violation of the method of the $t$ test, performing the nonparametric Mann-Whitney test adds confidence to the existence and significance of the breakpoints. Additionally, our correction of the significance values because of the multiplicity problem or multiple tests also adds strength to the breakpoint results.

[23] For the two series that included enough pre-K-T data (the Site 528 asymbiotic and intermediate series), the tests were run across the K-T boundary to determine whether the data included a statistical breakpoint at the K-T boundary. A K-T breakpoint was indeed significant in both series. See auxiliary material $^{1}$ to view the Mann-Whitney results for the $\mathrm{K}-\mathrm{T}$ breakpoint analysis. For both sites the $t$ test and the Mann-Whitney test yield almost identical breakpoints (see Table 1). It is not surprising that the breakpoint analyses across the K-T interval generally detect the K-T boundary, a physically marked boundary in the cores, as a distinct breakpoint. Most previous analysts have consistently recognized that the end of the Cretaceous collapse of surface ocean $\delta^{13} \mathrm{C}$ values occurs at the impact debris horizon that defines the K-T boundary [Hsü et al., 1982; Arthur et al., 1987; Zachos and Arthur, 1986; Zachos et al., 1989; Stott and Kennett, 1989; D'Hondt et al., 1998].

[24] On the basis of the Mann-Whitney results, the primary recovery breakpoint identified for the Site 528 surface and intermediate gradients was between 16.79 and $18.33 \mathrm{~m}$ above the K-T boundary (Table 1). Because the asymbiotic series ends near the primary breakpoints of the other data series at this site $(\sim 17 \mathrm{~m}$ above the K-T boundary), we cannot use the asymbiotic series to test for a breakpoint at the depth of the other series' primary breakpoints.

[25] Both the intermediate and surface data series from Site 528 show secondary breakpoint peaks $\sim 5 \mathrm{~m}$ above the K-T boundary (Table 1 ). The principal recovery breakpoint in the Site 528 asymbiotic series is also $\sim 5 \mathrm{~m}$ above the K-T boundary (Table 1). The concurrence of these breakpoints provides statistical evidence of an early recovery period $\sim 500,000$ years after the extinction. This early recovery period coincides with the recovery period identified by Zachos et al. [1989] and Stott and Kennett [1989] and described as the "early recovery" interval by D'Hondt et al. [1998].

[26] The pattern of recovery breakpoints at Site 577 closely resembles that at Site 528. For Site 577 a breakpoint between 7.19 and $7.99 \mathrm{~m}$ above the K-T boundary was determined in the surface series, and a breakpoint between 5.49 and $5.59 \mathrm{~m}$ above the K-T boundary was identified in the intermediate series in Table 1. Both of these breakpoints occur between $\sim 61$ and $\sim 62.5 \mathrm{Ma}$. Except for the short Site 528 asymbiotic data series, the timing of the primary breakpoints in all of the analyzed series from Sites 528 and 577 was between $\sim 61$ and $\sim 62.5 \mathrm{Ma}$ (see especially Figures 1, 3, 4, and 5).

\subsection{Chi-Square Goodness-of-Fit Model Analysis}

[27] Tables 2, 3, and 4 show the general and detailed results of the best fit model analyses. All three series have significant

\footnotetext{
${ }^{1}$ Auxiliary material is available at ftp://ftp.agu.org/apend/pa/ 2002 PA000849.
} 

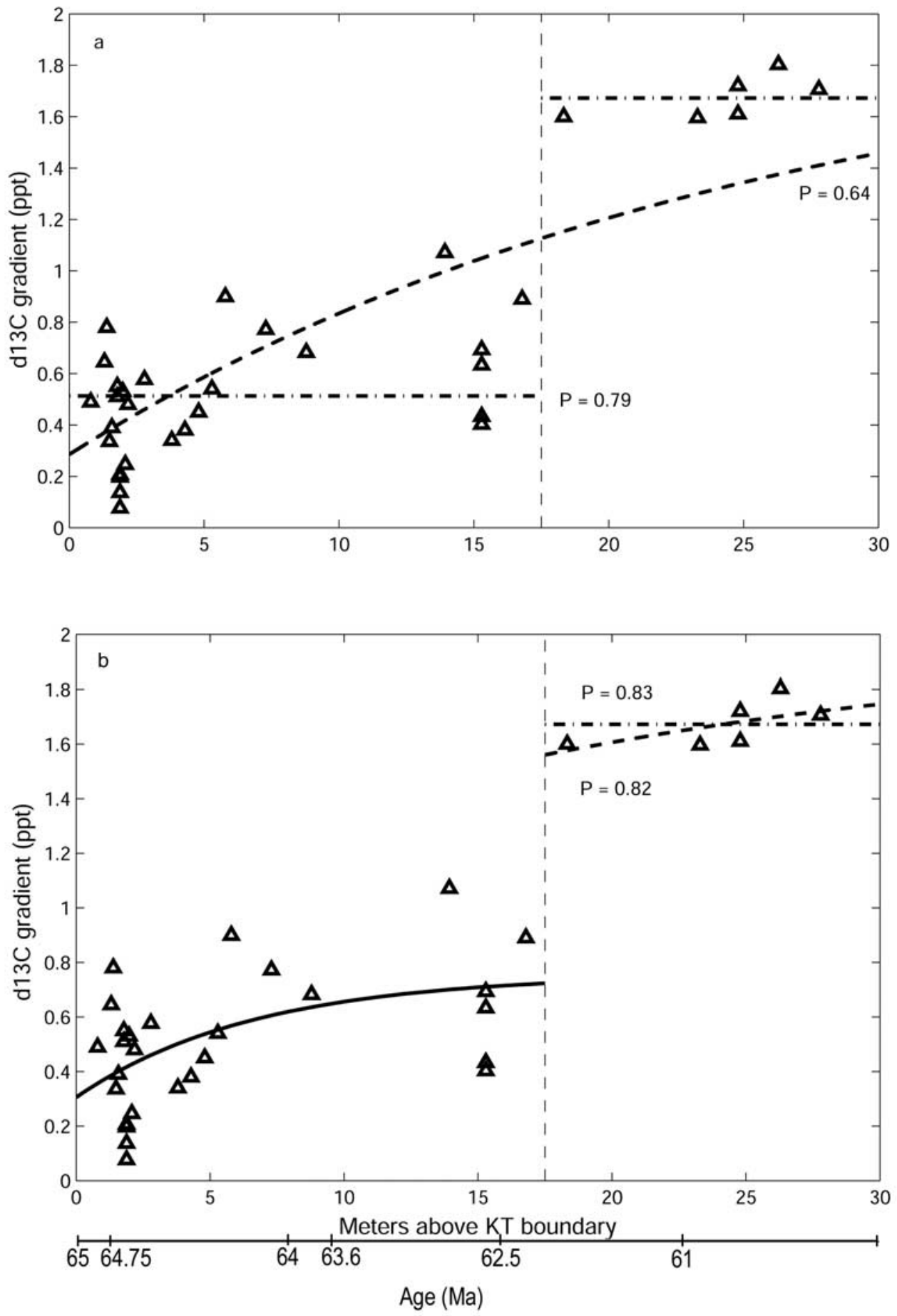

Figure 1. Recovery models and respective $P$ values for DSDP Site 528 surface-benthic $\delta^{13} \mathrm{C}$ difference data. (a) Two-mean and single-exponential and (b) initial exponential and double-exponential recovery models. The solid line is a "universal" recovery (either mean or exponential) that is shared by both models in a given graph. Dashed-dotted lines represent mean models not shared by the other model in the graph. Dashed lines are exponential recovery models not shared by the other model in the graph. Triangles show surface-benthic $\delta^{13} \mathrm{C}$ gradient data points. 

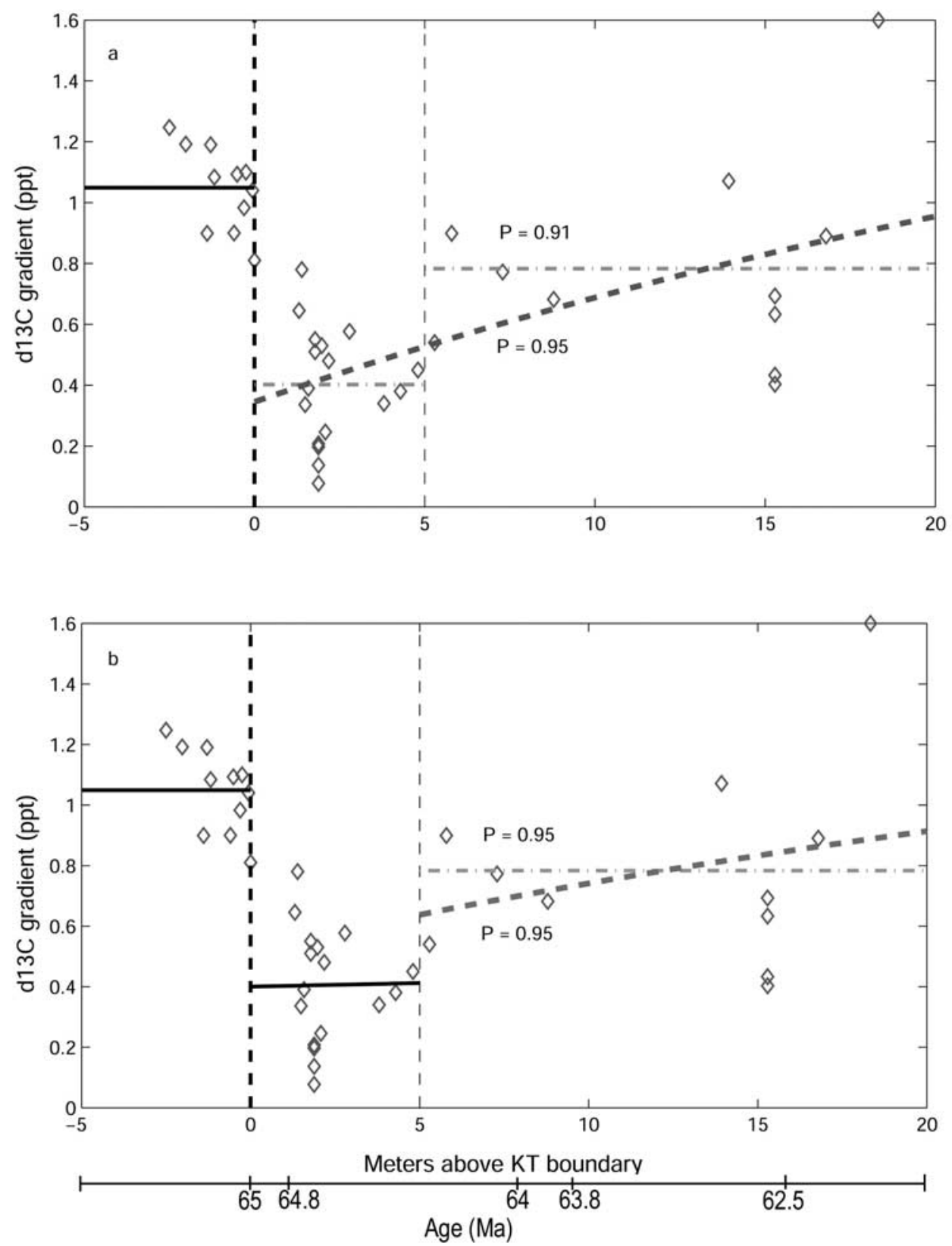

Figure 2. Recovery models and respective $P$ values for DSDP Site 528 asymbiotic surface-benthic $\delta^{13} \mathrm{C}$ difference. Model types are same as for Figure 1. (a) Two-mean and single-exponential and (b) initial exponential and double-exponential recovery models. Diamonds show asymbiotic surface-benthic $\delta^{13} \mathrm{C}$ gradient data points.

serial correlation coefficients, and thus the effective sample sizes (i.e., $N^{\prime}$ ) are smaller than the actual sample sizes. Figures $1-5$ display the nature and strength of the models for each data series (see auxiliary material ${ }^{2}$ figures). All data sets exhibit a preference for a model including a negative exponential recovery period between the K-T boundary and the statistically established recovery breakpoint. This preference for an initial negative exponential recovery period, across all sites, is interesting to note in light of the great spatial separation of the two sites.
[28] It should be noted that the best model fits for the Site 528 surface-benthic gradient series are not as strong as for the other series. This weakness can be attributed to the very small effective sample size at which the $\chi^{2}$ values are evaluated (the strong serial correlation of these two series greatly reduces the strength of the fit). The reduced $\chi^{2}$ values for the residuals of the best models are found in Table 5 . Reduced $\chi^{2}$ values of $\sim 1$ or less suggest Gaussian residuals. The Site 528 data are approximately Gaussian, and the Site 577 intermediate-benthic data appear to be non-Gaussian. 

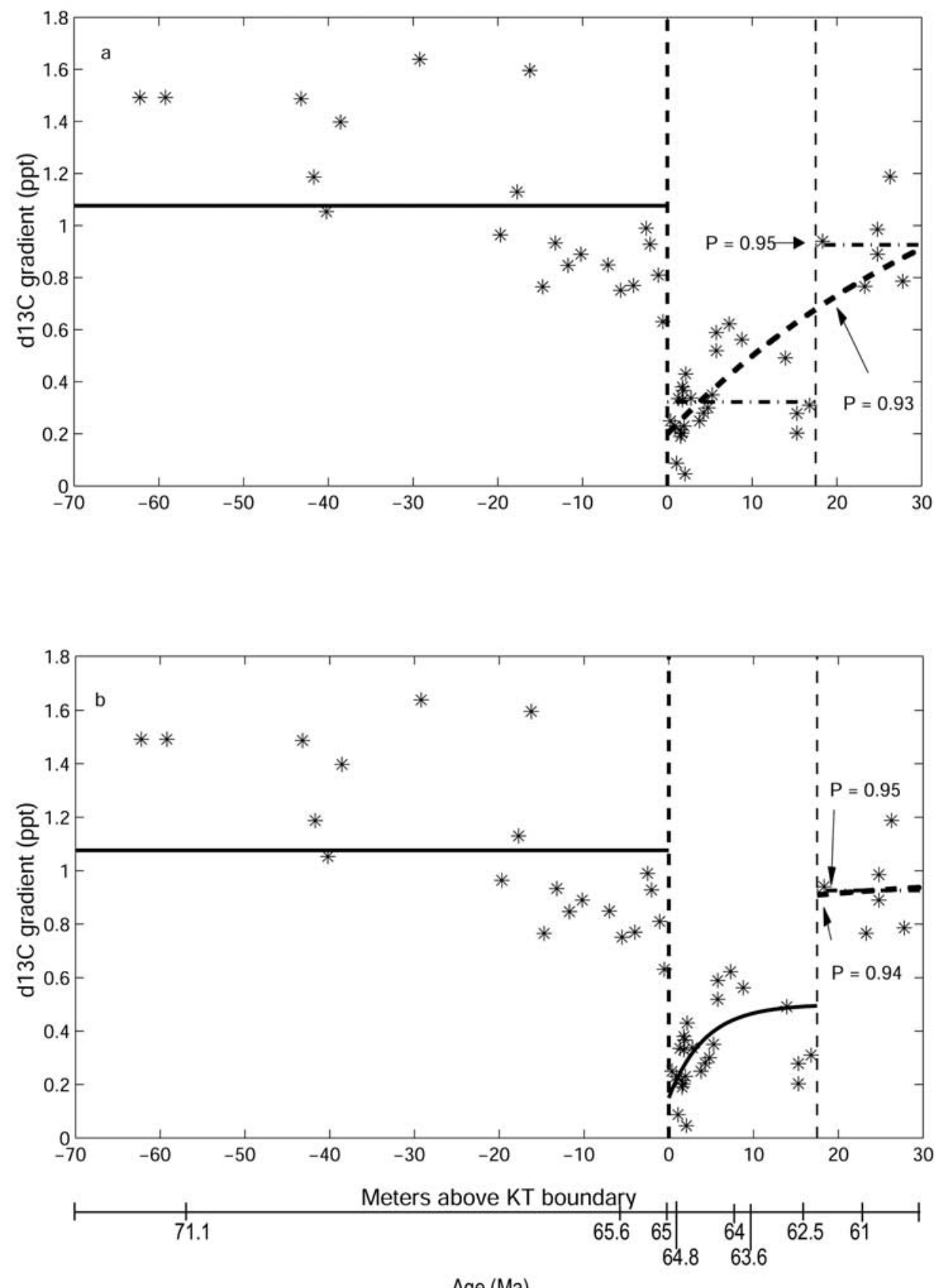

Age (Ma)

Figure 3. Recovery models and respective $P$ values for DSDP Site 528 intermediate-benthic $\delta^{13} \mathrm{C}$ difference. Model types are same as for Figure 1. (a) Two-mean and single-exponential and (b) initial exponential and double-exponential recovery models. Asterisks show intermediate-benthic $\delta^{13} \mathrm{C}$ gradient data points.

[29] After approaching relatively stable mean values in the upper portion of the initial negative exponential recovery period, all data series jump to a relatively stable condition similar to preextinction levels at the stratigraphic depth of the primary recovery breakpoints in the Site 528 surface and intermediate series and the Site 577 surface series (Figures 1-5). The stratigraphic interval of these breakpoints approximately corresponds to the depth of the foraminiferal zone $\mathrm{P} 1 / \mathrm{P} 2$ boundary [D'Hondt et al., 1998].

\section{Discussion}

[30] These results provide quantitative support for (1) a distinct decrease in planktic-to-benthic $\delta^{13} \mathrm{C}$ differences at the K-T boundary and (2) a two-stage postboundary 

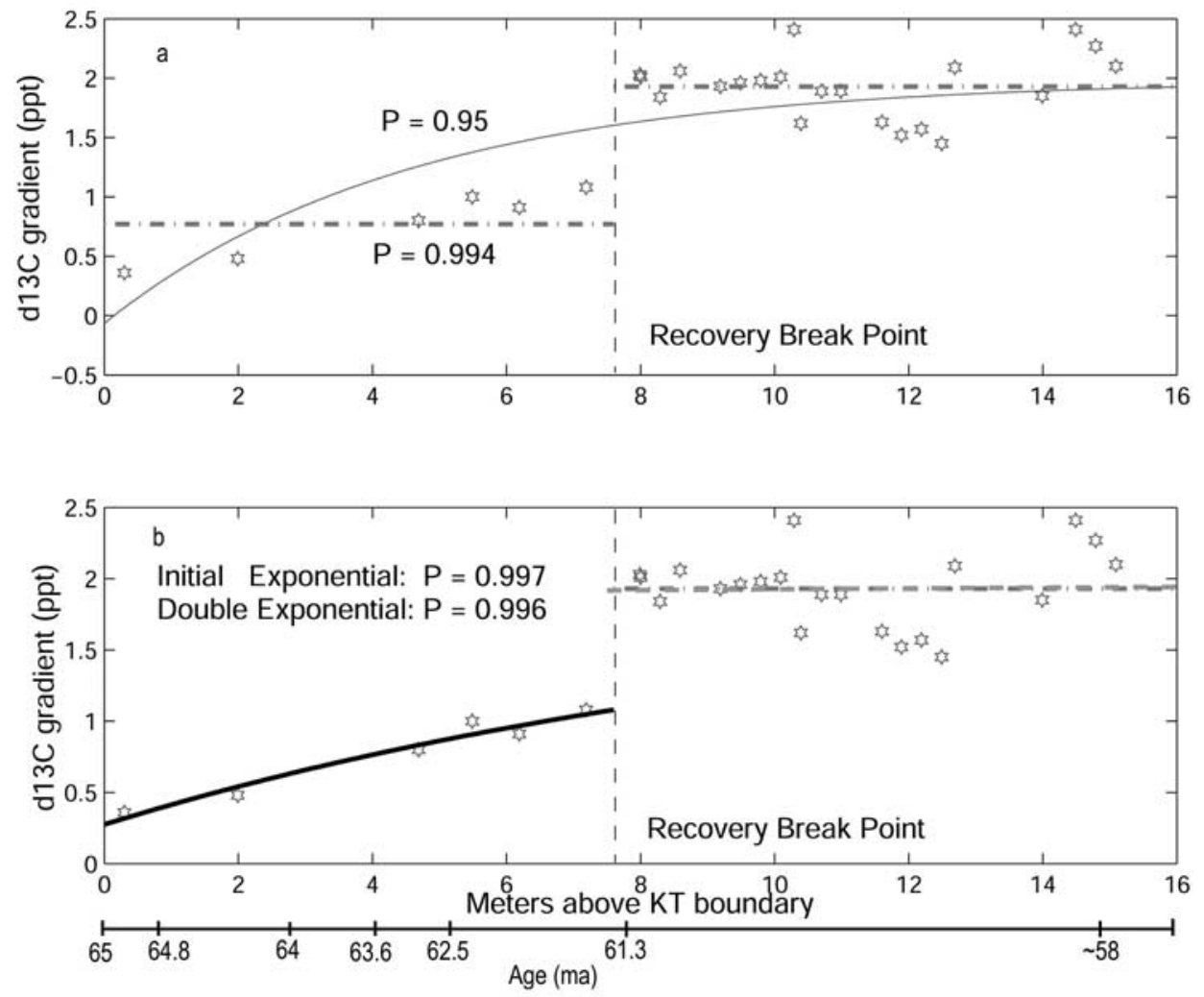

Figure 4. Recovery models and respective $P$ values for DSDP Site 577 surface-benthic $\delta^{13} \mathrm{C}$ difference. Model types are same as for Figure 1. (a) Two-mean and single-exponential and (b) initial exponential and double-exponential recovery models. Stars show surface-benthic $\delta^{13} \mathrm{C}$ gradient data points. Bold curve is used for both initial recovery period models. Light curve shows models preferred in only one of the recovery scenarios.

recovery of planktic-to-benthic $\delta^{13} \mathrm{C}$ differences to higher values. This two-stage recovery consists of a continuous initial relaxation toward a temporary state of relatively low $\delta^{13} \mathrm{C}$ differences, followed by a discontinuous adjustment to near preboundary isotopic values nearly 4 Myr after the K-T event. The fact that all the data from both the Pacific site and the Atlantic site are best fit by recovery models of similar form (i.e., both initial, negative exponential recovery and a discontinuous stable final recovery) supports the global extent of this open ocean $\delta^{13} \mathrm{C}$ response to the $\mathrm{K}-\mathrm{T}$ extinction. Furthermore, the temporal coincidence of the breakpoints identified for both sites provides statistical evidence of a globally consistent recovery to the K-T extinction.

[31] The breakpoint results are important because they suggest a quite significant, distinct initial recovery period (stage 1), followed by a discontinuous jump to a state of equilibrium (stage 2). The initial recovery period best matches a negative exponential recovery model. As noted in section 3.1, this initial stage of recovery corresponds to the recovery period identified by Zachos et al. [1989] and Stott and Kennett [1989] and described as the early recovery interval by D'Hondt et al. [1998]. During this early stage the recovery appears to have taken the form of a continuous gradual increase toward relatively low planktic-to-benthic $\delta^{13} \mathrm{C}$ differences. This pattern of early recovery is consistent with a continuous gradual recovery of the organic flux from the surface ocean to the deep ocean.

[32] The breakpoint analyses of the surface and intermediate data series from Sites 528 and 577 indicate that this early stage of continuous recovery (stage 1) was followed by a discontinuous jump to a state of equilibrium (stage 2) nearly $4 \mathrm{Myr}$ after the K-T boundary. After this final recovery event, planktic-to-benthic $\delta^{13} \mathrm{C}$ differences were close to preimpact differences. This disjointed recovery suggests the oceanic carbon system reacted discontinuously in its postextinction recuperation. If preimpact and postimpact $\delta^{13} \mathrm{C}$ differences are interpreted in the usual manner (as representing the flux of organic carbon from the surface ocean to the deep ocean), then this two-stage $\delta^{13} \mathrm{C}$ recovery corresponds to a two-stage recovery of the mean organic flux from the surface ocean to the deep ocean.

[33] It would be very difficult to reconcile the long delay in final recovery of the oceanic carbon system with any purely physical model of impact consequences (such as darkness due to the atmospheric loading of postimpact dust) [Arthur et al., 1987; Stott and Kennett, 1989]. As noted in section 1, most proximate effects of the K-T impact (such as global darkness and acid rain) are modeled to have lasted 

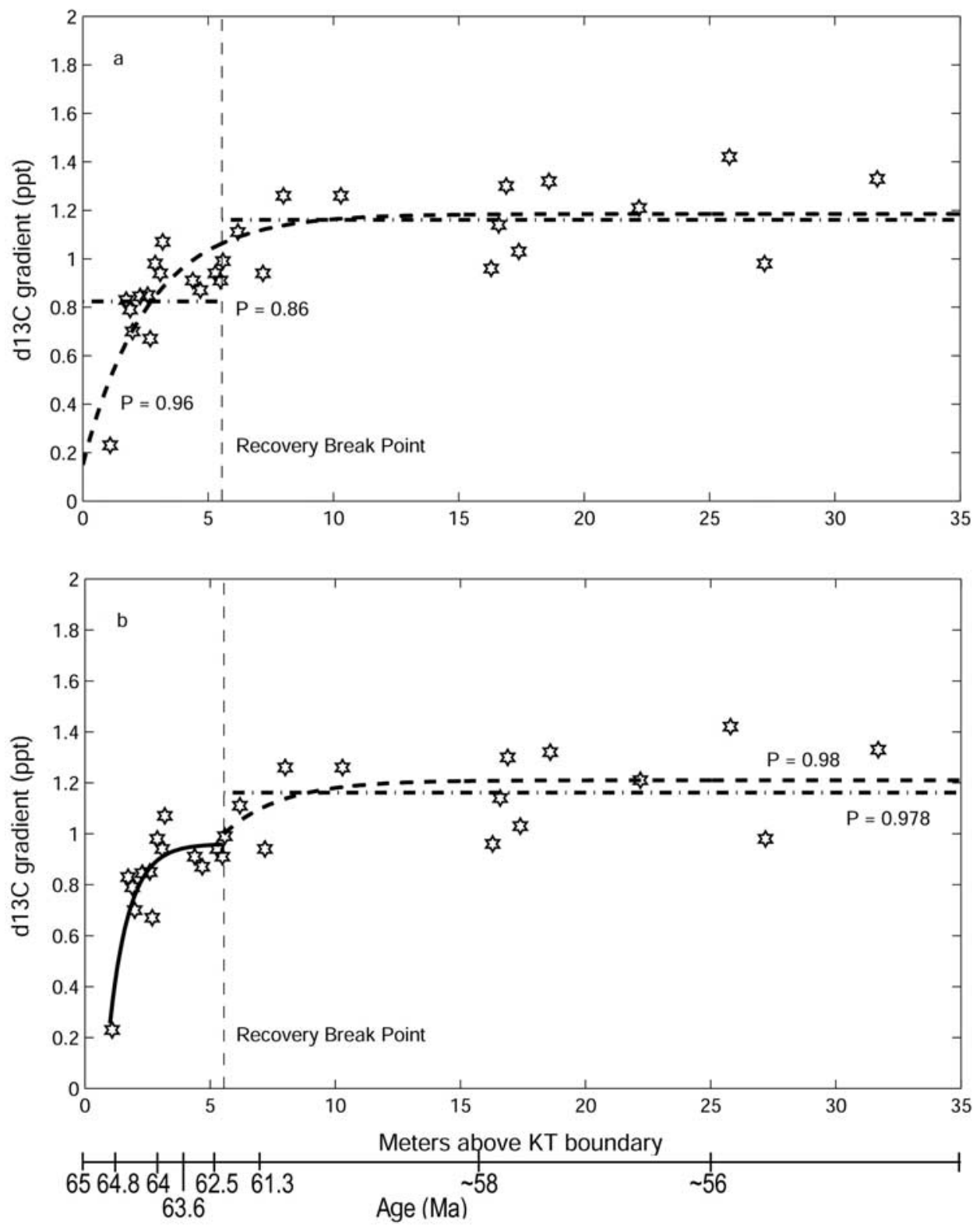

Figure 5. Recovery models and respective $P$ values for DSDP Site 577 intermediate-benthic $\delta^{13} \mathrm{C}$ difference. Model types are same as for Figure 1. (a) Two-mean and single-exponential and (b) initial exponential and double-exponential recovery models. Stars show intermediate-benthic $\delta^{13} \mathrm{C}$ gradient data points.

less than a few decades, and none have been modeled to last several million years [e.g., Kring, 2000].

[34] However, the long delay in final recovery of the marine carbon cycle can be reconciled with biological models of mass extinction and recovery [Arthur et al., 1987]. The two-stage pattern of recovery can also be reconciled with biological models of mass extinction and recovery. The long delay and the two-stage recovery pattern are readily compatible with the living ocean model of D'Hondt et al. [1998]. They are also potentially consistent with a low-productivity Strangelove ocean model.
[35] The living ocean model assumes that marine biological production recovered as daylight returned following the impact and that the unusually low planktic-to-benthic $\delta^{13} \mathrm{C}$ differences of the early Paleocene resulted from an unusually low fraction of marine production sinking to the deep ocean. If we apply this model to the post-K-T recovery of planktic-to-benthic $\delta^{13} \mathrm{C}$ differences, then the stage 1 interval of continuously recovering $\delta^{13} \mathrm{C}$ differences primarily resulted from a continuous increase in the fraction of marine biological production that sank to the deep ocean. With this model the stage 2 interval of discontinuous recovery of $\delta^{13} \mathrm{C}$ differences would have similarly resulted from a rapid 
Table 2. Best Fit Models

\begin{tabular}{lclc}
\hline Site & $\delta{ }^{13} \mathrm{C}$ Gradient & "Best Fit" Model & Significance $P$ \\
\hline 528 & surface-benthic & initial exponential & 0.83 \\
528 & asymbiotic surface-benthic & double exponential & 0.95 \\
528 & intermediate-benthic & initial exponential & 0.95 \\
577 & surface-benthic & initial exponential & 0.99 \\
577 & intermediate-benthic & double exponential & 0.98 \\
\hline
\end{tabular}

increase in the fraction of marine biological production that sank to the deep ocean.

[36] The living ocean model effectively assumes that the recovery of marine carbon fluxes was contingent on the recovery of ecosystem structure. From this perspective the first stage of organic flux recovery corresponded to an early postextinction interval of gradual ecological recovery and the second discontinuous stage of recovery resulted from a later rapid reorganization of ecosystem structure. The recovery of ecosystem structure may in turn have been contingent on one or more key biological events (such as a key evolutionary innovation), with the final discontinuous carbon system recovery occurring at the approximate time of the final key biological event(s).
[37] Within the context of a living ocean model, rapid reorganization in stage 2 could have resulted from any one of many different ecological events. For example, the proportion of organic matter that sank from the surface ocean to the deep ocean would have rapidly increased if mean phytoplankton size increased (e.g., if coccolithophorids or diatoms displaced photosynthetic bacteria in portions of the world ocean) or if higher trophic levels had increased their packaging of organic waste in relatively large coherent particles (e.g., if bony fish and/or copepods began to crop a greater fraction of primary production) [D'Hondt et al., 1998].

[38] Whatever its ecological cause, the stage 2 increase in the flux of organic matter from the surface ocean to the deep ocean could have initiated a new round of biological diversification. For example, the increased flux of organic matter to the deep sea would have stripped standing biomass and biologically limiting nutrients from the surface ocean. The resultant decrease in prey density (for zooplankton) and nutrient availability (for phytoplankton) could in turn have initiated diversification of photosymbioses in middle Paleocene oceans. Such a diversification of photosymbiotic taxa is exemplified by the middle Paleocene diversification of photosymbiotic planktic foraminiferal

Table 3. Chi-Square Goodness-of-Fit Test for Site 528

\begin{tabular}{|c|c|c|c|}
\hline Fit Type Evaluated at $\left(N^{\prime}\right)$ & $\begin{array}{c}\text { Effective } \\
\chi^{2}\end{array}$ & $\begin{array}{c}P \\
\text { Value } \\
\end{array}$ & Equation $^{\mathrm{a}}$ \\
\hline \multicolumn{4}{|c|}{ Surface-Benthic (2.5) } \\
\hline Single exponential & 0.88 & 0.64 & $Y=1.985-1.7^{\mathrm{b}} \exp (0.039 x)$ \\
\hline Double exponential & 0.39 & 0.82 & $\begin{array}{l}Y_{1}=0.755-0.45^{\mathrm{b}} \exp (-0.151 x) \\
Y_{2}=1.985-0.95^{\mathrm{b}} \exp (-0.046)\end{array}$ \\
\hline Mean only & 0.50 & 0.79 & $Y_{1}=0.5121, Y_{2}=1.6725$ \\
\hline Initial exponential $^{\mathrm{c}}$ & 0.38 & 0.83 & $\begin{array}{l}Y_{1}=0.755-0.45^{\mathrm{b}} \exp (-0.151 x) \\
Y_{2}=1.6725\end{array}$ \\
\hline \multicolumn{4}{|c|}{ Asymbiotic Surface-Benthic (12.3) } \\
\hline Single-exponential recovery ${ }^{\mathrm{c}}$ & 5.17 & 0.95 & $\begin{array}{l}Y_{1}=1.0489 \\
Y_{2}=1.895-1.55^{\mathrm{b}} \exp (-0.025)\end{array}$ \\
\hline Double-exponential recovery ${ }^{\mathrm{c}}$ & 5.13 & 0.95 & $\begin{array}{l}Y_{1}=1.0489 \\
Y_{2}=0.5-0.1^{\mathrm{b}} \exp (-0.025 x) \\
Y_{3}=1.52-\exp (-0.025 x)\end{array}$ \\
\hline Mean only recovery & 6.12 & 0.91 & $\begin{array}{l}Y_{1}=1.0489 \\
Y_{2}=0.4019 \\
Y_{3}=0.7833\end{array}$ \\
\hline Initial exponential recovery ${ }^{\mathrm{c}}$ & 5.18 & 0.95 & $\begin{array}{l}Y_{1}=1.0489 \\
Y_{2}=0.5-0.1^{\mathrm{b}} \exp (-0.025 x) \\
Y_{3}=0.7833\end{array}$ \\
\hline \multicolumn{4}{|c|}{ Intermediate-Benthic (7.8) } \\
\hline Single-exponential recovery & 2.47 & 0.93 & $\begin{array}{l}Y_{1}=1.076 \\
Y_{2}=1.55-1.35^{\mathrm{b}} \exp (-0.025 x)\end{array}$ \\
\hline Double-exponential recovery & 2.33 & 0.94 & $\begin{array}{l}Y_{1}=1.076 \\
Y_{2}=0.5-0.35^{\mathrm{b}} \exp (-0.235 x) \\
Y_{3}=0.995-0.15^{\mathrm{b}} \exp (-0.032 x)\end{array}$ \\
\hline Mean only recovery ${ }^{\mathrm{c}}$ & 2.23 & 0.95 & $\begin{array}{l}Y_{1}=1.076 \\
Y_{2}=0.3225 \\
Y_{3}=0.9258\end{array}$ \\
\hline Initial exponential recovery ${ }^{c}$ & 2.20 & 0.95 & $\begin{array}{l}Y_{1}=1.076 \\
Y_{2}=0.5-0.35^{\mathrm{b}} \exp (-0.235 x) \\
Y_{3}=0.9258\end{array}$ \\
\hline
\end{tabular}

\footnotetext{
${ }^{\mathrm{a}} Y$ is the gradient value, and $x$ is the location above the K-T boundary.

${ }^{\mathrm{b}}$ The surface- and intermediate-to-benthic gradients both contained two points after the K-T boundary that were similar in magnitude to the pre-K-T values. These values were removed for the best fit analysis.

"Statistically "preferred" models for a given data series.
} 
Table 4. Chi-Square Goodness-of-Fit Test for Site 577

\begin{tabular}{|c|c|c|c|}
\hline Fit Type, Evaluated at $N^{\prime}$ & Effective $\chi^{2}$ & $P$ Value & Equation $^{\mathrm{a}}$ \\
\hline \multicolumn{4}{|c|}{ Surface-Benthic (11.3) } \\
\hline Single-exponential recovery & 4.57 & 0.95 & $Y=1.985-2.05^{\mathrm{b}} \exp (-0.221 x)$ \\
\hline Double-exponential recovery ${ }^{c}$ & 2.46 & 0.996 & $\begin{array}{l}Y_{1}=1.925-1.65^{\mathrm{b}} \exp (-0.088 x) \\
Y_{2}=1.985-0.1^{\mathrm{b}} \exp (-0.053 x)\end{array}$ \\
\hline Mean only recovery & 2.65 & 0.994 & $Y_{1}=0.7717, Y_{2}=1.9295$ \\
\hline Initial exponential recovery ${ }^{\mathrm{c}}$ & 2.25 & 0.997 & $\begin{array}{l}Y_{1}=1.925-1.65^{\mathrm{b}} \exp (-0.088 x) \\
Y_{2}=1.9295\end{array}$ \\
\hline \multicolumn{4}{|c|}{ Intermediate-Benthic (10) } \\
\hline Single-exponential recovery & 3.66 & 0.96 & $Y=1.185-1.035^{\mathrm{b}} \exp (-0.385 x)$ \\
\hline Double-exponential recovery ${ }^{c}$ & 3.04 & 0.98 & $\begin{array}{l}Y_{1}=0.96-2.485^{\mathrm{b}} \exp (-1.26 x) \\
Y_{2}=1.21-2.36^{\mathrm{b}} \exp (-0.435 x)\end{array}$ \\
\hline Mean only recovery & 5.39 & 0.86 & $Y_{1}=0.8239, Y_{2}=1.161$ \\
\hline Initial exponential recovery & 3.14 & 0.979 & $\begin{array}{l}Y_{1}=0.96-2.485^{\mathrm{b}} \exp (-1.26 x) \\
Y_{2}=1.161\end{array}$ \\
\hline
\end{tabular}

\footnotetext{
${ }^{\mathrm{a}} Y$ is the gradient value, and $x$ is the location above the $\mathrm{K}-\mathrm{T}$ boundary.

${ }^{\mathrm{b}}$ The surface- and intermediate-to-benthic gradients both contained two points after the K-T boundary that were similar in magnitude to the pre-K-T values. These values were removed for the best fit analysis.

${ }^{\mathrm{c}}$ Statistically preferred models for a given data series.
}

species (Morozovella and Acarinina) [D'Hondt et al., 1994; Norris, 1996]. This diversification nearly doubled the standing diversity of planktic foraminifera [Olsson et al., 1999]. In short, a living ocean model implies that the recovery of ecosystem structures may occur in multiple stages, measures of ecological structure may exhibit more than one equilibrium state, and biological diversification need not be continuous.

[39] The Strangelove ocean model effectively assumes that a fixed proportion of marine biological production sinks to the deep ocean and that the low planktic-to-benthic $\delta^{13} \mathrm{C}$ differences of the early Paleocene resulted from an unusually low level of marine production. If we apply a lowproductivity Strangelove ocean model to the two-stage recovery of planktic-to-benthic $\delta^{13} \mathrm{C}$ differences, then the first stage of organic flux recovery corresponded to an interval of gradually increasing marine biological production, and the second discontinuous stage corresponded to a later rapid return to the preimpact level of marine biological production.

[40] Marine biological production could have been held below its preimpact level for millions of years if some key physical property (such as the incidence of light) was also below its preimpact level for the same interval of time. However, it is very difficult to sustain this interpretation or any other Strangelove ocean interpretation that relies on a purely physical model of impact (because the physical effects of large-body impacts do not persist on million year timescales) [Arthur et al., 1987].

[41] Marine biological production could also have been held below its preimpact level if the oceanic concentration of a key nutrient (such as dissolved phosphorus or iron) was held below its preimpact level. Such an interpretation would require that the oceanic concentration of the limiting nutrient decline precipitously at the time of impact, gradually recover over several (1-3) million years toward low but relatively stable values, and then discontinuously recover to an approximately preimpact level nearly $4 \mathrm{Myr}$ after the impact and extinction event.

[42] Possible effects of the K-T impact and mass extinction on oceanic nutrient cycles have not been closely examined. The physical consequences of large body impacts are not obviously linked to precipitous declines in oceanic nutrient concentrations. Also, given the long timescale of early Paleocene $\delta^{13} \mathrm{C}$ recovery and the short timescale of modeled impact consequences, it appears likely that any long-term disruption of oceanic nutrient cycles would be a likelier consequence of biogeochemical disruption by the mass extinction (such as postextinction modification of biologically enhanced weathering processes) than of direct physical or chemical disruption by large body impact. Given this circumstance, with a nutrient-limited Strangelove ocean model the first stage of $\delta^{13} \mathrm{C}$ difference recovery marks an interval of continuous recovery of some key biogeochemical process, and the second stage marks the final discontinuous recovery of that process. As with the recovery of ecosystem structure in the living ocean model, any such final recovery of a key nutrient cycle may in turn have been contingent on a key biological event, with the final discontinuous carbon system recovery occurring at the approximate time of the key biological event.

[43] It is not crucial to this study whether the two-stage, multimillion year recovery of planktic-to-benthic $\delta^{13} \mathrm{C}$ differences is ultimately explained by a living ocean model or a low-productivity Strangelove ocean model. Independent of such explanations, the study provides

Table 5. Testing the Residuals for Gaussian Normalcy

\begin{tabular}{lcc}
\hline Site & Best Recovery Models & Reduced $\chi^{2}$ \\
\hline 528 & surface initial exponential & 1.04 \\
528 & asymbiotic surface double exponential & 0.54 \\
528 & intermediate initial exponential & 0.54 \\
577 & surface initial exponential & 0.85 \\
577 & intermediate double exponential & 1.74 \\
\hline
\end{tabular}


statistical evidence for the timing and pattern of plankticto-benthic $\delta^{13} \mathrm{C}$ difference recovery. The study also illustrates how application of the quantitative methods employed in this study can enhance understanding of postextinction carbon flux recovery. Its results suggest that the post-K-T recovery of the open ocean carbon cycle occurred in two stages and consequently may have been contingent on the occurrence of key biological events. Understanding the exact nature of those events will require comparison to other kinds of paleobiological and paleoceanographic data.

[44] Acknowledgments. This research was supported by NSF grant EAR 9814790. All samples were provided by the Ocean Drilling Program and its predecessor, the Deep Sea Drilling Project. The authors appreciate the helpful manuscript comments of Scott Rutherford (URI).

\section{References}

Arthur, M. A. (1979), Sedimentologic and geochemical studies of Cretaceous and Paleogene pelagic sedimentary rocks: The Gubbio sequence, Ph.D. dissertation, Princeton Univ., Princeton, N. J.

Arthur, M. A., J. C. Zachos, and D. S. Jones (1987), Primary productivity and the Cretaceous/Tertiary boundary event in the oceans, Cretaceous Res., 8, 43-45.

Barrera, E., and G. Keller (1994), Productivity across the Cretaceous/Tertiary boundary in high latitudes, Geol. Soc. Am. Bull., 106, 1254-1266.

Berggren, W. A., and R. D. Norris (1999), Biostratigraphy, in Atlas of Paleocene Planktonic Foraminifera, edited by R. K. Olsson et al., Smithson. Contrib. Paleobiol., 85, 8-10.

Berggren, W. A., D. V. Kent, C. C. Swisher III, and M.-P. Aubry (1995), A revised Cenozoic geochronology and chronostratigraphy, in Geochronology, Timescales and Global Stratigraphic Correlation, edited by W. A. Berggren, Spec. Publ. SEPM Soc. Sediment. Geol., 54, 129-212.

Bevington, P. R. (1969), Data Reduction and Error Analysis for the Physical Sciences, McGraw-Hill, New York.

Bleil, U. (1985), The magnetostratigraphy of northwest Pacific sediments, Deep Sea Drilling Project Leg 86, Initial Rep. Deep Sea Drill. Proj., 86, 441-458.

Boersma, A. (1984), Campanian through Paleocene paleotemperature and carbon isotope sequence and the Cretaceous-Tertiary boundary in the Atlantic Ocean, in Catastrophes and Earth History: The New Uniformitarianism, edited by W. A. Berggren and J. A. van Couvering, pp. 247-278, Princeton Univ. Press, Princeton, N. J.

Boersma, A., N. J. Shackleton, M. Hall, and Q. Given (1979), Carbon and oxygen isotope at DSDP Site 384 (North Atlantic) and some paleotemperatures and carbon isotope variations in the Atlantic Ocean, Initial Rep. Deep Sea Drill. Proj., 43, 695-717.

Broecker, W. S., and T.-H. Peng (1982), Tracers in the Sea, 620 pp., Lamont-Doherty Earth Obs., Palisades, N. Y.

Cande, S. C., and D. V. Kent (1995), Revised calibration of the geomagnetic polarity timescale for the Late Cretaceous and Cenozoic, J. Geophys. Res., 100(B4), 6093-6095.

Chave, A. D. (1984), Lower Paleocene-Upper Cretaceous magnetostratigraphy, Sites 525, 527, 528, and 529, Deep Sea Drilling Project Leg 74, Initial Rep. Deep Sea Drill. Proj., 74, $525-532$.

Cook, R. J., and V. T. Farewell (1996), Multiplicity considerations in the design and analysis of clinical trials, J. R. Stat. Soc., Ser. A, 159, 93- 110 .

Corfield, R. M., and J. E. Cartlidge (1992), Oceanographic and climatic implications of the Paleocene carbon isotope maximum, Terra Nova, 4(4), 443-455.

D'Hondt, S. (1998), Isotopic proxies for ecological collapse and recovery from mass extinctions in Isotope Paleobiology and Paleoecology, edited by R. D. Norris and R. M. Corfield, Pap. 4, pp. 179-211, Paleontol. Soc., Pittsburgh, $\mathrm{Pa}$.

D'Hondt, S., and M. Lindinger (1994), A stable isotopic record of the Maastrichtian ocean-climate system: South Atlantic DSDP Site 528, Palaeogeogr. Palaeoclimatol. Palaeoecol., 112, 363-378.

D'Hondt, S., and J. C. Zachos (1993), On stable isotopic variation and earliest Paleocene planktonic foraminifera, Paleoceanography, 8(4), $527-547$.

D'Hondt, S., and J. C. Zachos (1998), Cretaceous foraminifera and the evolutionary history of planktic photosymbiosis, Paleobiology, 24(4), 512-523.

D'Hondt, S., J. C. Zachos, and G. Schultz (1994), Stable isotopic signals and photosymbiosis in late Paleocene planktic foraminifera, Paleobiology, 20(3), 391-406.

D'Hondt, S., T. D. Herbert, J. King, and C. Gibson (1996), Planktic foraminifera, asteroids, and marine production: Death and recovery at the Cretaceous-Tertiary boundary, in New Developments Regarding the K-T Event and Other Catastrophes in Earth History, Spec. Pap. Geol. Soc. Am., 307, $303-$ 317.

D'Hondt, S., P. Donaghay, J. C. Zachos, D. Luttenberg, and M. Lindinger (1998), Organic carbon fluxes and ecological recovery from the Cretaceous-Tertiary mass extinction, Science, 282, 276-279.

Erwin, D. H. (1998), The end and the beginning: Recoveries from mass extinctions, Trends Ecol. Evol., 13, 344-349.

Erwin, D. H. (2000), Lessons from the past: Biotic recoveries from mass extinctions, Proc. Natl. Acad. Sci. U. S. A., 98, 53995403

Heath, G. R., et al. (1985), Initial Reports of the Deep Sea Drilling Project (1985), vol. 86, U.S. Govt. Print. Off., Washington, D.C.

Hsü, K. J., and J. McKenzie (1985), A “Strangelove" ocean in the earliest Tertiary, in The Carbon Cycle and Atmospheric $\mathrm{CO}_{2}$ : Natural Variations Archean to Present, Geophys. Monogr. Ser., vol. 32, edited by W. S. Broecker and E. T. Sundquist, pp. 487-492, AGU, Washington, D. C

Hsü, K. J., et al. (1982), Mass mortality and its environmental and evolutionary consequences, Science, 216, 249-256.

Keller, G., and M. Lindinger (1989), Stable isotope, TOC and $\mathrm{CaCO}_{3}$ record across the Cretaceous-Tertiary boundary at El Kef, Tunisia, Palaeogeogr. Palaeoclimatol. Palaeoecol., 73, 243-265.
Kirchner, J. W., and A. Weil (2000), Delayed biological recovery from extinctions throughout the fossil record, Nature, 404, 177-180.

Kring, D. A. (2000), Impact events and their effect on the origin, evolution, and distribution of life, GSA Today, 10(8), 1-7.

Melosh, H. J. (1989), Impact Cratering: A Geologic Process, Oxford Monogr. Geol. Geophys., vol. 11, 245 pp., Oxford Univ. Press, New York.

Miller, K. G., T. R. Janecek, M. E. Katz, and D. J. Keil (1987), Abyssal circulation and benthic foraminiferal changes near the Paleocene/Eocene boundary, Paleoceanography, 2(6), 741 761.

Moore, T. C., Jr., et al. (1984), Initial Reports of the Deep Sea Drilling Project, vol. 74, U.S. Govt. Print. Off., Washington, D.C.

Norris, R. D. (1996), Symbiosis as an evolutionary innovation in the radiation of Paleocene planktic foraminifera, Paleobiology, 22(4), $461-480$.

Olsson, R. K., C. Hemleben, W. A. Berggren, and B. T. Huber (Eds.) (1999), Atlas of Paleocene Planktonic Foraminifera, Smithson. Contrib. Paleobiol., 85, 252 pp.

Sclater, J. G., L. Meinke, A. Bennett, and C. Murphy (1985), The depth of the ocean through the Neogene, in The Miocene Ocean: Paleoceanography and Biogeography, Mem. Geol. Soc. Am., 163, 1-20.

Sepkoski, J. J., Jr. (1998), Rates of speciation in the fossil record, Philos. Trans. R. Soc. London, Ser. B., 353, 315-326.

Shackleton, N. J., R. M. Corfield, and M. A. Hall (1985), Stable isotope data and the ontogeny of Paleocene planktonic foraminifera, J. Foraminiferal Res., 15(4), 321-336.

Stott, L. D., and J. P. Kennett (1989), New constraints on early Tertiary palaeoproductivity from carbon isotopes in foraminifera, Nature, 342, 526-529.

Stott, L. D., and J. P. Kennett (1990), The paleoceanographic and paleoclimatic signature of the Cretaceous/Tertiary boundary in the Antarctic: Stable isotopic results from ODP Leg 113, Proc. Ocean Drill. Program Sci. Results, 113, 829-848.

Wilks, D. S. (1995), Statistical Methods in the Atmospheric Sciences: An Introduction, Academic, San Diego, Calif.

Zachos, J. C., and M. A. Arthur (1986), Paleoceanography of the Cretaceous-Tertiary boundary event: Inferences from stable isotopic and other data, Paleoceanography, 1(1), $5-26$.

Zachos, J. C., M. A. Arthur, R. C. Thunell, D. F. Williams, and E. J. Tappa (1985), Stable isotope and trace element geochemistry of carbonate sediments across the Cretaceous/Tertiary boundary at Deep Sea Drilling Project Hole 577, Leg 86, Initial Rep. Deep Sea Drill. Proj., $86,513-532$. 
Zachos, J. C., M. A. Arthur, and W. E. Dean (1989), Geochemical evidence for suppression of pelagic marine productivity at the Cretaceous/Tertiary boundary, Nature, 337, 61-64.

Zachos, J. C., M.-P. Aubry, W. A. Berggren, T. Ehrendorfer, and F. Heider (1992), Magnetobiochemostratigraphy across the Cretaceous/ Paleogene boundary at ODP Site 750A, South- ern Kerguelen Plateau, Proc. Ocean Drill. Program Sci. Results, 120, part 2, 961-977.

J. B. Adams and M. E. Mann, Department of Environmental Sciences, University of Virginia, Clark Hall, 291 McCormick Rd., P.O. Box
400123, Charlottesville, VA 22904-4123, USA. (brad.adams@wg.srs.com; mem6u@virginia. edu)

S. D'Hondt, Graduate School of Oceanography, University of Rhode Island, Narragansett Bay Campus, 100A Horn Building, South Ferry Road, Narragansett, RI 02882, USA. (dhondt@ gso.uri.edu) 